\title{
Electrical Testing of the Full-Scale Model of the NSTX HHFW Antenna Array*
}

\author{
P. M. Ryan, D. W. Swain, J. B. Wilgen, A. Fadnek, D. O. Sparks \\ Oak Ridge National Laboratory, Oak Ridge, TN ,37831-8071,
}

\begin{abstract}
The $30 \mathrm{MHz}$ high harmonic fast wave (HHFW) antenna array for NSTX consists of 12 current straps, evenly spaced in the toroidal direction. Each pair of straps is connected as a half-wave resonant loop and will be driven by one transmitter, allowing rapid phase shift between transmitters. A decoupling network using shunt stub tuners has been designed to compensate for the mutual inductive coupling between adjacent current straps, effectively isolating the six transmitters from one another. One half of the array, consisting of six full-scale current strap modules, three shunt stub decouplers, and powered by three phase-adjustable of amplifiers had been built for electrical testing at ORNL. Low power testing includes electrical characterization of the straps, operation and performance of the decoupler system, and mapping of the rf fields in three dimensions.
\end{abstract}

\section{SIX-ELEMENT, FULL-SCALE MOCKUP ARRAY}

The power distribution/phase control system for the NSTX HHFW 12-element antenna array was designed using the FDAC coupled transmission line code [1-3]. Antenna

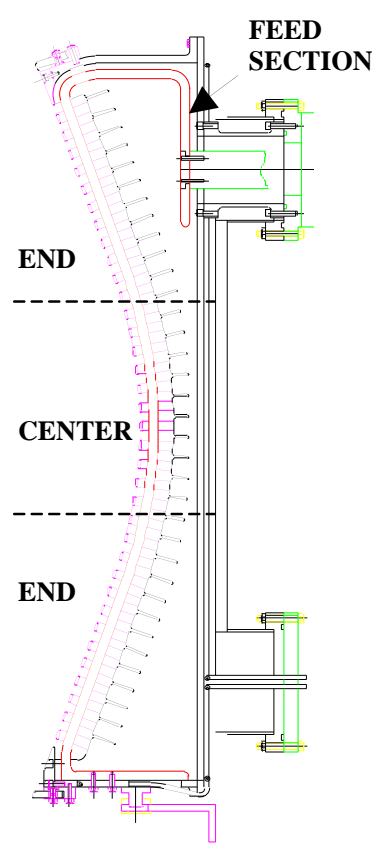

FIGURE 1. NSTX Current Strap

parameters for the transmission line model were calculated from 2D magnetostatic codes; each antenna strap was divided into four sections: two ends, a center,

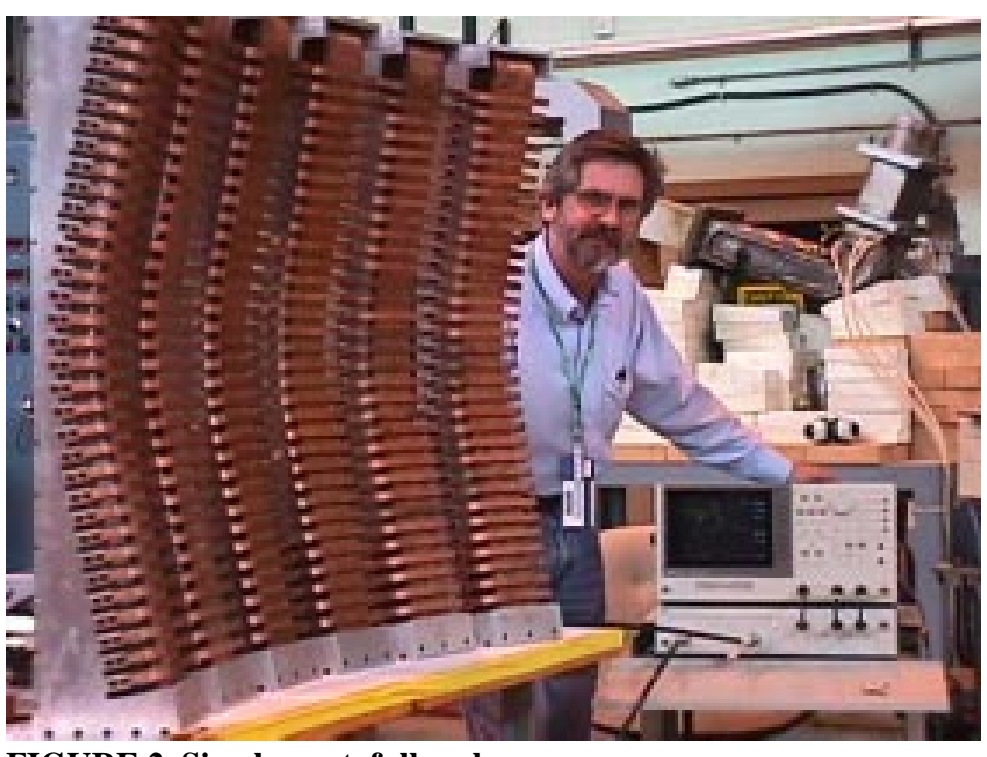

FIGURE 2. Six-element, full scale mockup of the NSTX HHFW array.

*Oak Ridge National Laboratory, managed by Lockheed Martin Energy Research Corp. for the U.S.

Department of Energy under contract number DE-AC05-96OR22464. 
and a radial feed (Fig. 1). The analysis predicts that six transmitters should deliver 6 MW total power to the plasma at $30 \mathrm{MHz}$ with the peak antenna voltages remaining below $25 \mathrm{kV}$ and peak system voltages below $35 \mathrm{kV}$, providing the expected plasma loading is at least $4 \Omega / \mathrm{m}$. Stub decouplers between resonant loops are expected to keep the magnitude of the strap currents within a few percent and their phase within a few degrees of optimum when the phase of the transmitters is varied, if the plasma loading can be held relatively constant through plasma position control $(\sim 2.5 \mathrm{~cm}$ shift in plasma edge can compensate for a factor of two change in loading.)

Six full-scale mockups of the NSTX antenna modules were fabricated and assembled to form a 6-element array (Fig. 2). The purpose was to check the electrical characteristics of the straps against the values used in the design of the power distribution system, test the performance of the phase control system, develop procedures for tuning the resonant loops, decouplers, and matching network, and make measurements of the field patterns of the array.

\section{COMPARISON OF MOCKUP MEASUREMENTS TO SYSTEM DESIGN}

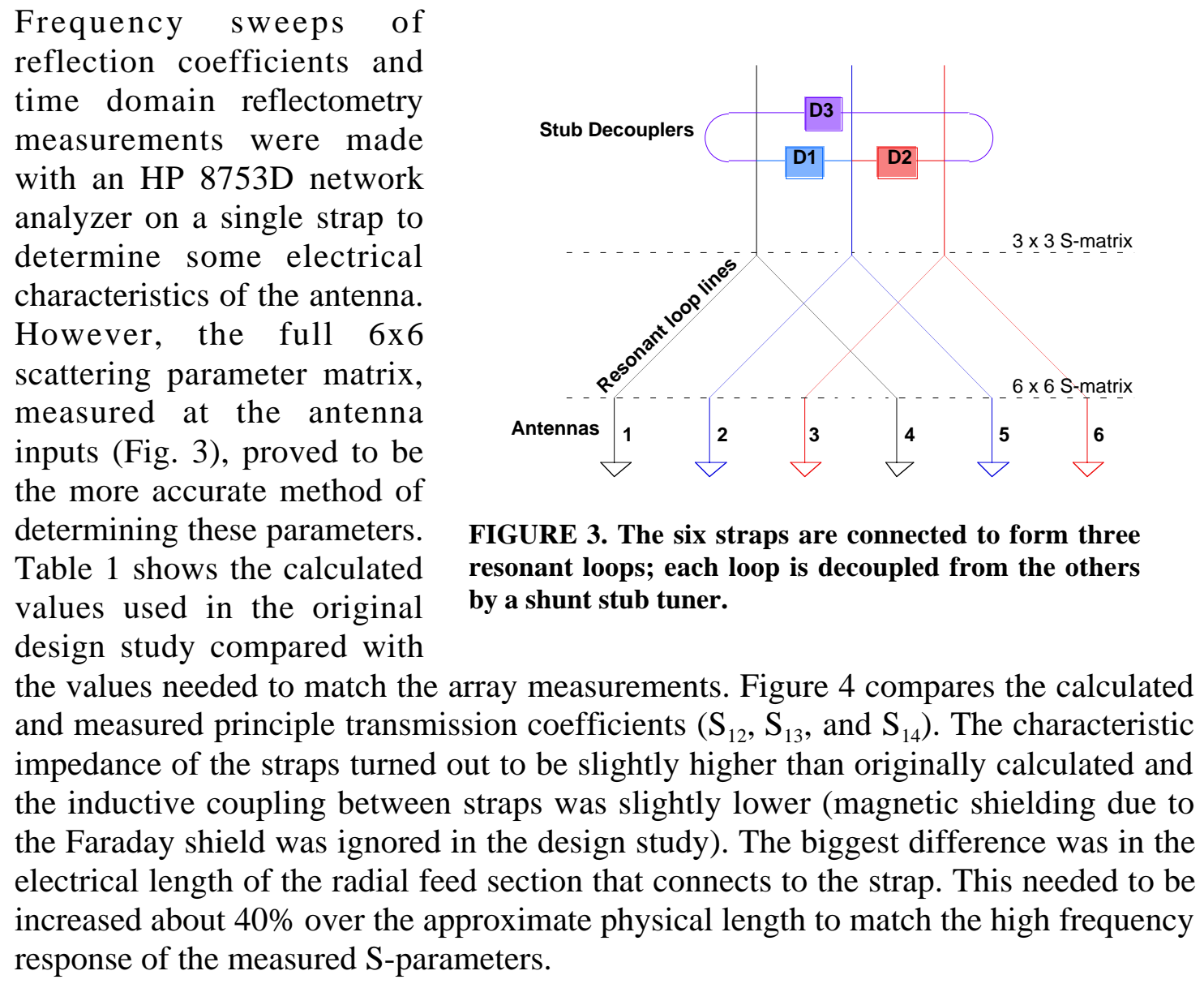

FIGURE 3. The six straps are connected to form three resonant loops; each loop is decoupled from the others by a shunt stub tuner. design study compared with the values needed to match the array measurements. Figure 4 compares the calculated and measured principle transmission coefficients $\left(S_{12}, S_{13}\right.$, and $\left.S_{14}\right)$. The characteristic impedance of the straps turned out to be slightly higher than originally calculated and the inductive coupling between straps was slightly lower (magnetic shielding due to the Faraday shield was ignored in the design study). The biggest difference was in the electrical length of the radial feed section that connects to the strap. This needed to be increased about $40 \%$ over the approximate physical length to match the high frequency response of the measured S-parameters. 
TABLE 1 Comparison of original calculated values to measurements

\begin{tabular}{|l|l|c|c|}
\hline \multicolumn{2}{|c|}{} & $\begin{array}{l}\text { Calculated Design } \\
\text { Values }\end{array}$ & $\begin{array}{l}\text { Values To Match Mockup } \\
\text { Measurements }\end{array}$ \\
\hline $\begin{array}{l}\text { Strap } \\
\text { Inductance }\end{array}$ & Center & $2.81 \mathrm{e}-7 \mathrm{H} / \mathrm{m}$ & $2.94 \mathrm{e}-7 \mathrm{H} / \mathrm{m}$ \\
\hline Strap & Ends & $3.39 \mathrm{e}-7 \mathrm{H} / \mathrm{m}$ & $3.57 \mathrm{e}-7 \mathrm{H} / \mathrm{m}$ \\
\hline Capacitance & Center & $1.21 \mathrm{e}-10 \mathrm{H} / \mathrm{m}$ & $1.12 \mathrm{e}-10 \mathrm{~F} / \mathrm{m}$ \\
\cline { 2 - 4 } & Ends & $1.21 \mathrm{e}-10 \mathrm{H} / \mathrm{m}$ & $1.08 \mathrm{e}-10 \mathrm{~F} / \mathrm{m}$ \\
\hline Phase Velocity & Center & $48 \Omega$ & $52 \Omega$ \\
\cline { 2 - 4 } & Ends & $53 \Omega$ & $58 \Omega$ \\
\hline Inductive & Center & $0.57 \mathrm{c}$ & $0.58 \mathrm{c}$ \\
\cline { 2 - 4 } Coupling, $\mathbf{k}_{\mathbf{1 2}}$ & Ends & $0.52 \mathrm{c}$ & $0.54 \mathrm{c}$ \\
\hline Inductive & Ender & 0.09 & 0.08 \\
Coupling, $\mathbf{k}_{\mathbf{1 3}}$ & Center & 0.14 & 0.10 \\
\hline Strap Length & Ends & $*$ & 0.02 \\
\cline { 2 - 4 } & Eenter & $0.30 \mathrm{~m}$ & 0.02 \\
\hline Feed Length & & $0.30 \mathrm{~m}$ & $0.285 \mathrm{~m}$ \\
\hline Feed $\mathbf{Z}_{\mathbf{0}}$ & & $0.20 \mathrm{~m}$ & $0.285 \mathrm{~m}$ \\
\hline
\end{tabular}

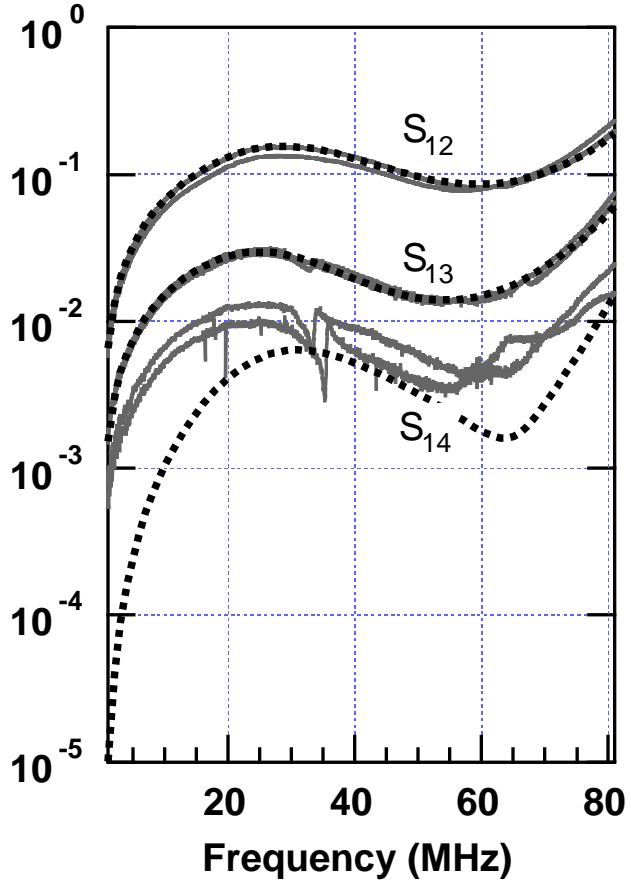

FIGURE 4. $S_{11}, S_{12}$, and $S_{13}$ as a function of frequency. Solid lines are measurements, dotted lines are calculations.
Strap pairs 1-4, 2-5, and 3-6 were connected together with RG-58 cables of lengths 5.33 and 10.24 $\mathrm{m}$ to form three loops, each resonant at approximately 30 $\mathrm{MHz}(29.95 \mathrm{MHz})$. The resonant lengths of each loop were set by shorting the other two loops at their T-feed point, which is normally a high impedance point. This detunes them sufficiently at $30 \mathrm{MHz}$ so they are decoupled from the test loop and do not respond to its excitation.

Figures 5a-c show the reflection and transmission coefficients of the 3x3 S-matrix measured at the inputs of the resonant loops (dotted lines are calculated from the model). Agreement between measurement and model could not be maintained over a large frequency range due to the dispersive nature of the RG-58 


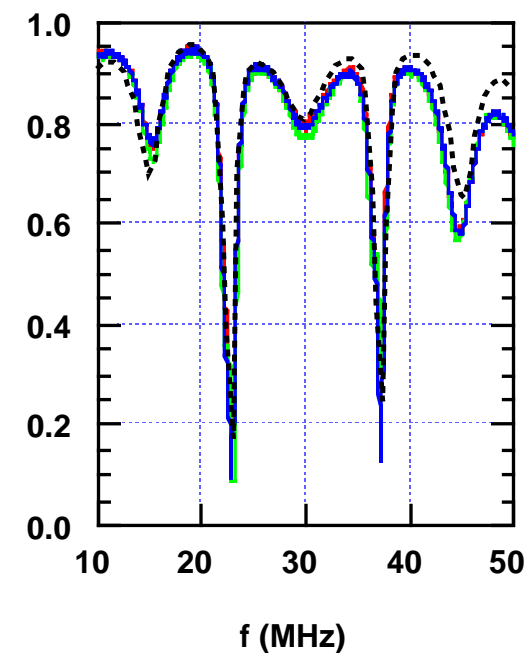

FIGURE 5a. $S_{11}, S_{22}, S_{33}$ at loop input

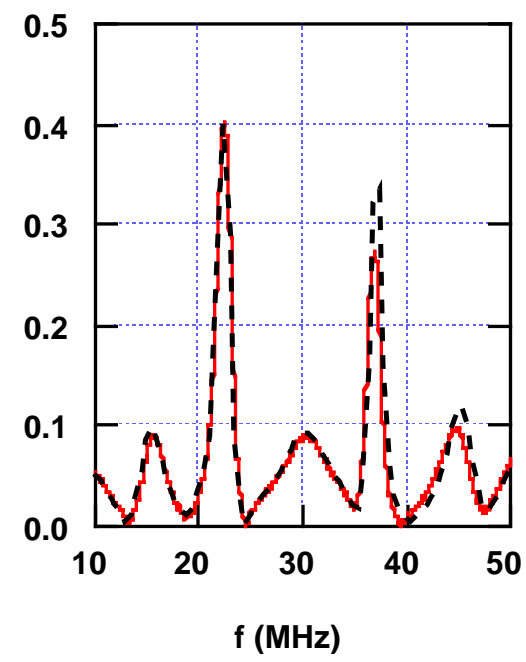

FIGURE 5c. $S_{13}$ at loop input

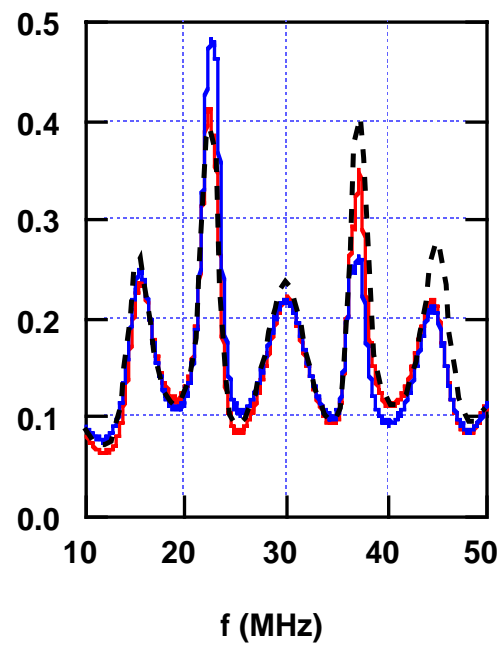

FIGURE 5b. $S_{12}, S_{23}$ at loop input

cable and BNC connections; the measured electrical length of the cables changed from 15.73 to $15.67 \mathrm{~m}$ as the frequency was increased from 28.6 to $52.6 \mathrm{MHz}$. These cables were chosen for reasons of availability and economy; the remainder of the power distribution system, including the decouplers, used RG-8 cable with Type $\mathrm{N}$ connectors.

\section{FOLLOW ON TESTING}

Decoupler D1 was adjusted to minimize $\mathrm{S}_{12}$ with D2 and D3 disconnected and loop 3 shorted at the T. Then D2 was connected and adjusted to minimize $S_{23}$ with D3 disconnected. Finally, D3 was

connected and adjusted; the $S_{12}, S_{23}$, and $S_{31}$ were between -30 and $-35 \mathrm{~dB}$ with the decouplers in place. The shunt lengths $(3.0$ and $2.5 \mathrm{~m})$ connecting the stub tuners have not yet been adjusted to their optimum lengths ( 2.67 and $2.36 \mathrm{~m}$ respectively) needed to minimize system voltages for a given power.

\section{REFERENCES}

[1] Ryan, P. M., et al, $2^{\text {nd }}$ Europhysics Topical Conference on Radio Frequency Heating and Current Drive of Fusion Devices, EPS Conf Abs 22A (Brussels, 1998) p. 97

[2] Bonanos, P., et al, Bull Amer Phys Soc 43 (New Orleans, 1998) p. 1863

[3] Ryan, P. M., et al, Bull Amer Phys Soc 43 (New Orleans, 1998) p. 1863 